\title{
CONSTRUCTION OF A RECOMBINANT ADENOVIRUS FOR THE EXPRESSION OF THE GLYCOPROTEIN S ANTIGEN OF PORCINE RESPIRATORY CORONAVIRUS
}

\author{
P. Callebaut ${ }^{1}$, M. Pensaert ${ }^{1}$ and L. Enjuanes ${ }^{2}$ \\ ${ }^{1}$ Laboratory of Virology, Faculty of Veterinary Medicine, University of Gent, \\ Casinoplein 24, B-9000 Gent, Belgium and ${ }^{2}$ Centro de Biologia Molecular \\ (CSIC-UAM), Facultad de Ciencias, Universidad Autonoma, Canto Blanco, \\ 28049 Madrid, Spain
}

\section{INTRODUCTION}

Efforts to develop respiratory and enteric vaccines focus on the efficient delivery of protective antigens to the mucosal lymphoid tissue. One approach is to use recombinant viral vectors, i.e. apathogenic viruses with a tropism for mucosal surfaces and genetically manipulated to express the protective antigens. Adenoviruses, particularly the human adenovirus type 5 (Ad5), are promising candidates for use as vectors.

Porcine respiratory coronavirus (PRCV) and transmissible gastroenteritis virus (TGEV) of swine are coronaviruses, showing complete two-way cross-neutralization, but having a tropism for different mucosae (Pensaert et al., 1986). They could present an attractive model to test the induction of immunity at both respiratory and enteric mucosal surfaces by an Ad5 vector capable of expressing the common neutralization mediating antigen.

In the present study, it was the purpose to assess preliminarily the suitability of Ad5 as a vector by inoculation in pigs. Furthermore, we describe the construction of a recombinant adenovirus (Ad5-gpS) which harbours an in vitro synthesized fragment of the peplomer glycoprotein (gpS) gene of PRCV. The fragment chosen encodes the N-terminal globular domain, carrying the neutralization epitopes (Correa et al., 1990; Rasschaert et al., 1990).

\section{INOCULATION OF PIGS WITH HUMAN Ad5}

Five conventional pigs at 4 weeks of age were inoculated oronasally with $7 \times 10^{9} \mathrm{pfu}$ of Ad5, grown and titrated in the human 293 cell line. They were observed daily for clinical signs. Two pigs were examined for seroconversion using paired serum samples, tested by the conventional seroneutralization (SN) test. The 3 remaining pigs were killed on days 3,5 and 7 after inoculation. Specimens of the tonsils and various parts of the respiratory and the enteric tract were examined for the presence of infectious Ad5 using standard virus isolation methods.

None of the pigs experienced respiratory or intestinal disorders. Two pigs, while having no SN antibodies at the time of inoculation, had SN-titers of 48 and 128, respectively, 4 weeks later. The clearcut seroconversion indicated that both pigs had been infected. Ad5 was consistently isolated from the tonsils, trachea and diafragmatic lobe of the lungs, indicating that the 3 killed pigs had been infected and that the virus had replicated in the 
tissues mentioned. Furthermore, the virus was present in the colon during the whole test period and in the ileum on day 5 after inoculation, suggesting that the virus had replicated in these segments of the intestinal tract. However, it cannot be excluded that the virus may have reached the gut by ingestion. Taken together, these findings provide preliminary evidence that Ad5 may be suitable as a gene transfer vector for the induction of mucosal immunity in the respiratory and digestive tract of pigs.

\section{CONSTRUCTION OF AN Ad5-gpS RECOMBINANT}

The virus source for the gpS gene fragment was PRCV isolate TLM 83 (Pensaert et al., 1986) at 3 passages in the swine testicle (ST) cell line. The genomic RNA was extracted from purified virus. The target $\mathrm{gpS}$ gene sequence, i.e. from 6 nucleotides upstream to 1692 nucleotides downstream of the gpS gene translation initiation codon, was synthesized in vitro by reverse transcription of the viral RNA to cDNA and subsequent amplification of the synthesized cDNA using the polymerase chain reaction process.

The construction of the Ad5-gpS recombinant was performed using standard molecular cloning techniques. It involved 3 consecutive steps. First, the $\mathrm{gpS}$ gene fragment was inserted in the plasmid pSV2X3 (Prevec et al., 1990). The resulting plasmid contained an expression cassette, which was a sequence composed of the early region promoter of simian virus (SV) 40 and the $\mathrm{gpS}$ fragment in the orientation that would allow transcription from the SV40 promoter, followed by the SV40 poly A addition signal. Subsequently, the cassette was inserted in the plasmid pFG144. This plasmid contains the left and right end sequences of the Ad5 genome. The right end sequences include the E3 region, except for a deletion which is not essential for the virus replication (Graham and Prevec, 1991). In the resulting plasmid, designated pFG/PRCV, the expression cassette was positioned in the deleted E3 region, in the same orientation as the E3 genes it replaced. Finally, the cloned recombinant Ad5 sequences in pFG/PRCV were rescued in infectious virus by transfection in 293 cells along with plasmid pFG173. The latter plasmid contains the complete Ad5 genome except for a lethal deletion which includes the E3 region (Graham and Prevec, 1991). Plaques of infectious Ad5 appeared 13 to 15 days after the cotransfection.

Recombinants were identified by measuring the level of expression of $\mathrm{gpS}$ antigen in cell lysates and supernatants from infected cell cultures using an antibody sandwich ELISA. The assay was essentially performed as described (Callebaut et al., 1982), using porcine antiTGEV immunoglobulins as the capture antibody and for the peroxidase conjugate preparation.

The cell lysates obtained following expansion of 10 plaques in 293 cells gave a positive signal in the ELISA. Because of the coding sequence which had been cloned it was assumed that the recognized antigen was the expected N-terminal domain of gpS of PRCV and that all plaques were recombinant. The concentration of $\mathrm{gpS}$ antigen in the lysates was calculated to be approximately $0.5 \mu \mathrm{g}$ per $10^{6}$ cells. The culture supernatants were consistently negative. Identical results were obtained following expansion of one of the plaques in ST cell cultures. Further work is in progress to study the in vivo expression and the induction of coronavirusneutralizing antibodies by inoculation of the recombinant in pigs.

\section{ACKNOWLEDGEMENTS}

This research is funded by the IWONL, Brussels

\section{REFERENCES}

Callebaut, P., Debouck, P., and Pensaert, M., 1982, Enzyme linked immunosorbent assay for the detection of the coronavirus-like agent and its antibodies in pigs with porcine epidemic diarrhea. Vet. Microbiol. 7: 295.

Correa, I., Gebauer, F., Bullido, M., Suné, C., Baay, M.F.D., Zwaagstra, K.A., Posthumus, W.P.A., Lenstra, and J.A., Enjuanes, L., 1990, Localization of antigenic sites of the E2 glycoprotein of transmissible gastroenteritis coronavirus. J. Gen. Virol.71: 271.

Graham, F.L., and Prevec, L., 1991, Manipulation of adenovirus vectors. In: "Methods in Molecular Biology" Murray, E.J., ed., Humana Press, 109.

Pensaert, M., Callebaut, P., and Vergote, J., 1986, Isolation of porcine respiratory, non-enteric coronavirus related to transmissible gastroenteritis. Vet. Quart. 8:257.

Prevec, L., Campbell, J.B., Christie, B.S., Belbeck, L., and Graham, F.L., 1990, A recombinant human adenovirus vaccine against rabies. J. Infect. Dis. 161: 27.

Rasschaert, D., Duarte, M., and Laude, H., 1990, Porcine respiratory coronavirus differs from transmissible gastroenteritis virus by a few genomic deletions. J. Gen. Virol. 71:2599. 